\title{
Ball-milling effect on Indonesian natural bentonite for manganese removal from acid mine drainage
}

\author{
Widyawanto Prastistho ${ }^{1,2^{*}}$, Winarto Kurniawan ${ }^{1}$, Hirofumi Hinode ${ }^{1}$ \\ ${ }^{1}$ Department of International Development Engineering, Tokyo Institute of Technology, 2-12-1, O-okayama, Meguro-ku, Tokyo $152-$ \\ 8550, Japan \\ ${ }^{2}$ Department of Environmental Engineering, Universitas Pembangunan Nasional "Veteran", Jl. SWK 104, Sleman, Daerah Istimewa \\ Yogyakarta 55283, Indonesia
}

\begin{abstract}
The influences of mechanical milling on Indonesian Natural Bentonite (INB) characteristics and manganese $(\mathrm{Mn})$ removal from acid mine drainage (AMD) were investigated. The INB characteristics were observed by scanning electron microscope (SEM), X-ray diffraction (XRD), nitrogen adsorption-desorption for specific surface area (SSA) and microporosity measurement, cation exchange capacity (CEC) and particle size distribution (PSD) analyzer. Four minutes milling with frequency $20 \mathrm{~Hz}$ on INB caused morphological change which showed more crumbled and destructed particle, lost the (001) peak but still retained the (100) peak that indicated delamination of montmorillonite mineral without breaking the tetrahedral-octahedral- tetrahedral (T-O-T) structure, rose the CEC from $28.49 \mathrm{meq} / 100 \mathrm{~g}$ to 35.51 $\mathrm{meq} / 100 \mathrm{~g}$, increase in the SSA from $60.63 \mathrm{~m} 2 / \mathrm{g}$ to $104.88 \mathrm{~m} 2 / \mathrm{g}$, significant increase in microporosity which described in the $t$ plots and decrease in the mean particle size distribution peak from $49.28 \mu \mathrm{m}$ to $38.84 \mu \mathrm{m}$. The effect of contact time and effect of adsorbent dosage on Mn sorption was studied. Both unmilled and milled samples reached equilibrium at 24 hours and the $\mathrm{pH}$ rose from 4 to 7 in first 30 minutes. The $\mathrm{Mn}$ removal percentage increased significantly after milling. Using Langmuir isotherm, the maximum adsorbed metals (qmax) also increased from 0.570 to $4.219 \mathrm{mg} / \mathrm{g}$.
\end{abstract}

\section{Introduction}

Bentonite, clay material containing montmorillonite minerals including to the smectite group, naturally formed by volcanic ash alteration or hydrothermal alteration, is widely used for environmental purposes such as adsorbent, radioactive barrier, liner disposal and so on due to its absorbability and low permeability $[1,2]$. Some modifications have been developed to improve bentonite sorption performance such as acid activation, pillaring, and milling [3,4,5]. Milling itself is non-chemical modification technique, usually using spinning jar with stainless still balls inside. The spinning jar causes pounding motion of the balls to the sample. This ball milling process reduces the bentonite particle size, change the morphology and crystal structure, exfoliation, increase at specific surface area (SSA) and cation exchange capacity (CEC), and improve heavy metal sorption performance [6,7]. Continuous milling will gradually affect montmorillonite crystal structural change which finally leads to amorphization. Intensive milling process gradually increased the SSA and CEC and reached the peak which then decreased [8].

This study is utilizing Indonesian natural bentonite (INB), located at Wonosegoro area, Boyolali district, Central Java, Indonesia which has hypothetical resource 58 million tons of natural bentonite [9]. Milling mechanical modification was conducted using small ball miller instead. Simple mechanism moving left right with one stainless steel ball inside at certain frequency that would give straight impact on the sample.

Milling modification of INB is applied for manganese $(\mathrm{Mn})$ removal from acid mine drainage (AMD). One of coal mining company in Jorong area, Tanah Laut district, South Kalimantan, Indonesia showed elevated $\mathrm{Mn}$ concentration with range 1.7 $\mathrm{mg} / \mathrm{L}-27.2 \mathrm{mg} / \mathrm{L}$ and $\mathrm{pH}$ 3.03-3.04 [10]. Indonesian government set the maximum limit of $\mathrm{Mn}$ concentration $0.1 \mathrm{mg} / \mathrm{L}$ for drinking water and $4 \mathrm{mg} / \mathrm{L}$ for mining waste. The difference is because the usage purposes. Indonesian government divides the water type into several classes considering the usage purpose. For instance, drinking water has different limit parameter with agricultural and fish cultivation purpose $[10,11]$. Indonesian natural bentonite and milling modification are considered as abundant low-cost material and low-cost treatment for AMD treatment.

\section{Material and methods}

\subsection{Field sampling and sample preparation}

Bentonite was taken from Wonosegoro area, Boyolali district, Central Java, Indonesia. Prior to sampling, outer bentonite exposed was dug $\pm 10 \mathrm{~cm}$ first in order 
to get uncontacted sample with the atmosphere. Sample was crushed using mortar and sieved pass $50 \mathrm{~mm}$ in order to get finer and relatively uniform particle size. The sample was then milled using Retsch MM 400. One gram sample was put inside grind jar (size $50 \mathrm{ml}$ ) and milled for 4 minutes with vibrational frequency setting was $20 \mathrm{~Hz}$.

\subsection{Characterization}

Crystal structural changes were observed using x-ray diffraction (XRD) equipment Rigaku Multiflex, operated at $40 \mathrm{kV}$ and $20 \mathrm{~mA}$. The XRD analyzer using Jade 5 software. Morphological changes were observed using Scanning electron microscope (SEM) Keyence VE-8800 with 3000 - 5000 times magnifications. Microporosity and SSA were measured using multiple- point nitrogen adsorption-desorption technique, with BELSORP-max. Particle size distribution measurements were made by SALD-2300 laser diffraction particle size analyzer. The CEC was determined using Chapman method by saturating the sample with sodium acetate and replacing sodium with ammonium acetate [12].

\subsection{Adsorption study}

Effect of contact time was investigated. Two portions $100 \mathrm{~mL}$ of $\mathrm{Mn}$ solutions with concentration of 27.48 $\mathrm{mg} / \mathrm{L}$ (diluted from Mn Wako standart solution 1000 ppm) with pH 4 were prepared in $100 \mathrm{~mL}$ beaker glasses. 1 gr unmilled and 4 minute-milled bentonite were added to each beaker glass. Magnetic stirrer was used to mix the bentonite and solution. The magnetic stirrer was set to 230 rotations per minute (RPM) at room temperature. The mixtures were sampled at $30 \mathrm{~m}, 1 \mathrm{~h}, 2 \mathrm{~h}, 4 \mathrm{~h}, 6 \mathrm{~h}, 12$ h, $24 \mathrm{~h}, 48 \mathrm{~h}$ and $72 \mathrm{~h}$.

Effect of sorbent dosage was investigated. Various mass of unmilled and 4 minutes milling bentonite were prepared $(0.4,0.6,0.8,1$ and $1.2 \mathrm{~g})$. The manganese solution was the same condition with the previous solution.

The concentration of all samples were measured using induced coupled plasma atomic emission spectroscopy (ICP-AES) Seiko Instrument, SPS 7800 (II). Adsorbed amount of Mn on INB then calculated using this equation:

$$
q=\frac{(\mathrm{Co}-\mathrm{Ce}) \mathrm{V}}{m}
$$

$\mathrm{q}=$ adsorbed manganese on sample $(\mathrm{mg} / \mathrm{g})$

$\mathrm{Co}=$ Initial concentration $(\mathrm{mg} / \mathrm{L})$

$\mathrm{Ce}=$ Final Concentration $(\mathrm{mg} / \mathrm{L})$

$\mathrm{V}=$ Solution volume $(\mathrm{ml})$

$\mathrm{m} \quad=$ Sample mass $(\mathrm{g})$

\section{Result and discussion}

\subsection{Characterization}

Fig. 1 (SEM photos) shows the morphological change before (a) and after 4 minutes milling (b). The morphology of milled bentonite appears more destructed, crumbled and more blunt angularity. The frequency also affected the change of morphology beside the milling time.
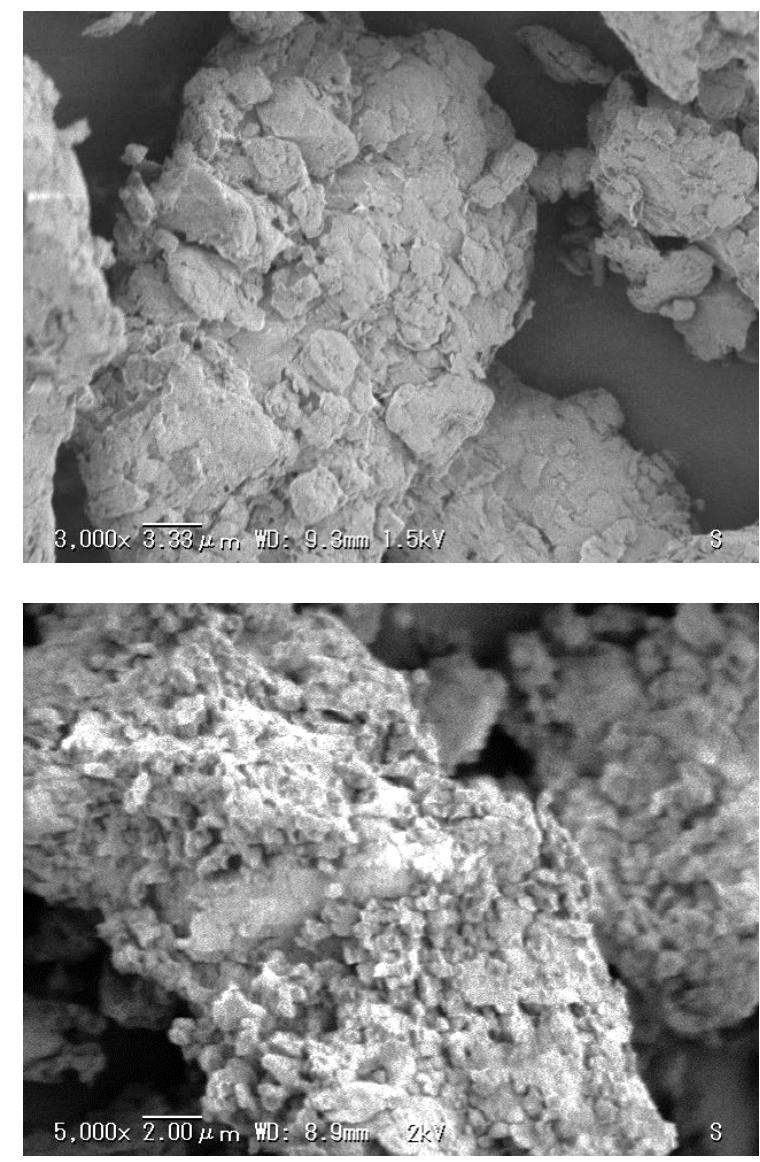

Fig. 1. SEM photo before (a) and after 4 minutes milling (b)

The Jade 5 XRD analyzer software did not exhibit any peak read of (001) montmorillonite after 4 minutes milling (Fig. 2). But the interesting found is it still retained the (100) without any structural change, indicating delamination of montmorillonite mineral without breaking the tetrahedral-octahedral-tetrahedral (T-O-T) structure. It is different from Vdović et al (2010) [8], the decrease in intensity of (001) followed by (100) together which finally both lost peak, indicated transformed to amorphous due to prolonged milling. Different miller and energy would probably give different effect on exfoliation and deformation phases of montmorillonite.

The initial CEC of INB was $28.49 \mathrm{meq} / 100 \mathrm{~g}$ and increased after 4 minutes milling to $35.51 \mathrm{meq} / 100 \mathrm{~g}$, attributed to disaggregation of INB which leads to more opened exchangeable cation on basal planes of montmorillonite 


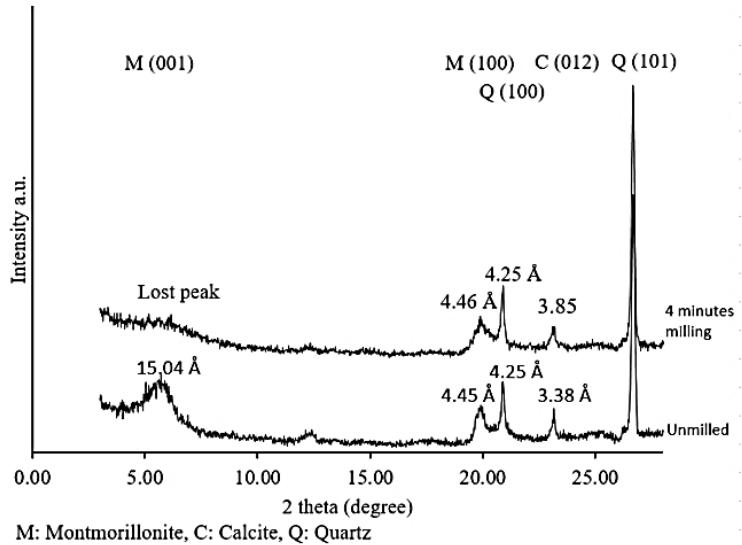

Fig. 2. XRD pattern of unmilled and milled bentonite

The $\mathrm{N}_{2}$ adsorption-desorption shows hysteresis, indicated the INB is porous material (Fig. 3). This hysteresis shape also confirmed the INB as slit pore shape (type B) [13]. After milling the hysteresis appears narrower. The initial SSA of unmilled INB, using Brunauer, Emmet, and Teller (BET) method, was $60.63 \mathrm{~m}^{2} / \mathrm{g}$, and increased after 4 minutes milling to $104.88 \mathrm{~m}^{2} / \mathrm{g}$.
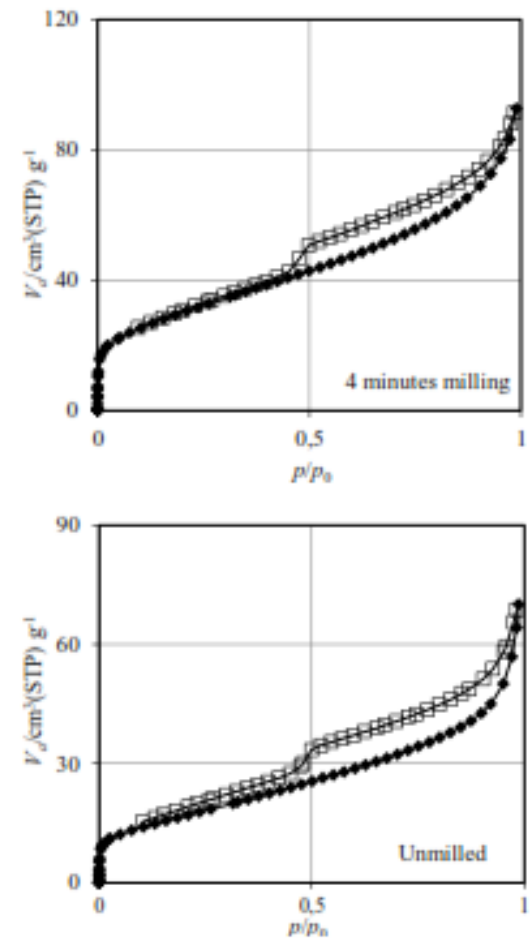

Fig.3. Adsorption-desorption isotherm of unmilled and 4 minutes milling INB

Significant increase in microporosity after milling is described in the t plots (Fig. 4, Table 1). The t-plot method, developed by Lippens and de Boer, is standard isotherm describes relationship between relative pressure and thickness of adsorption layer [14]. The thickness ( $t$ ) can be obtained from this equation:

$$
t=\frac{V_{a}}{V_{m}} x 0.354(\mathrm{~nm})
$$

$\mathrm{Va}$

$=$ volume of gas adsorbed $(\mathrm{mL})$
$\mathrm{Vm}=$ volume of monolayer gas adsorbed on the sample surface $(\mathrm{mL})$

The number $0.354 \mathrm{~nm}$ is the thickness of monomolecular layer where the nitrogen molecules considered as hexagonal on adsorbent surface, therefore, it is smaller than nitrogen molecule diameter.

The unmilled and milled INB t plots have two slopes that the one sharp and the other steeper, it means the sample is type (II) which indicates it has micropores [14].

The increase of micropore volume and micropore surface area are confirmed the particle disaggregation also opened new pores due to milling. On the other hand, the $2 \mathrm{t}$ did not significantly change. Initially phase of delamination only shifting along the basal planes [15]. Therefore, in this study, is assumed the delamination after 4 minutes milling the basal planes only shifted, and has not caused fully separation between T-O-T planes.
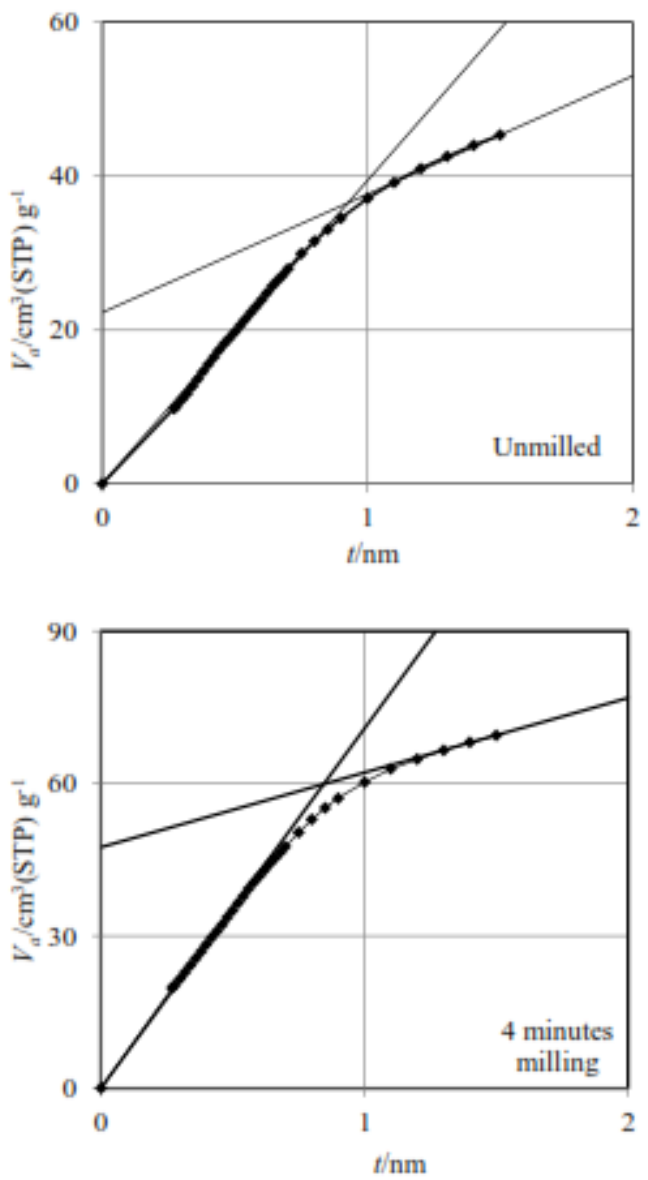

Fig. 4. t-plots of unmilled and 4 minutes milling of INB

Table 1. Micropore surface area, external surface area, micropore volume and $2 \mathrm{t}$ of unmilled and milled INB

\begin{tabular}{|c|c|c|c|c|}
\hline $\begin{array}{c}\text { Sample } \\
\text { condition }\end{array}$ & $\begin{array}{c}\text { Micropore } \\
\text { surface area } \\
\left(\mathrm{m}^{2} / \mathrm{g}\right)\end{array}$ & $\begin{array}{c}\text { External } \\
\text { surface } \\
\text { area } \\
\left(\mathrm{m}^{2} / \mathrm{g}\right)\end{array}$ & $\begin{array}{c}\text { Micropore } \\
\text { volume } \\
\left(\mathrm{cm}^{3} / \mathrm{g}\right)\end{array}$ & $\begin{array}{c}2 t \\
(\mathrm{~nm})\end{array}$ \\
\hline Unmilled & 60.73 & 23.70 & 0.034 & 1.85 \\
\hline $\begin{array}{c}4 \text { minutes } \\
\text { milling }\end{array}$ & 109.15 & 22.63 & 0.074 & 1.69 \\
\hline
\end{tabular}


The PSD curve before and after milling shown in Fig. 5. The PSD of unmilled INB, dominated by coarser particle population with mean $49.28 \mu \mathrm{m}$. After milling, the coarser population decreased to $38.84 \mu \mathrm{m}$. The finer particle population remains unchanged at $9.316 \mu \mathrm{m}$.

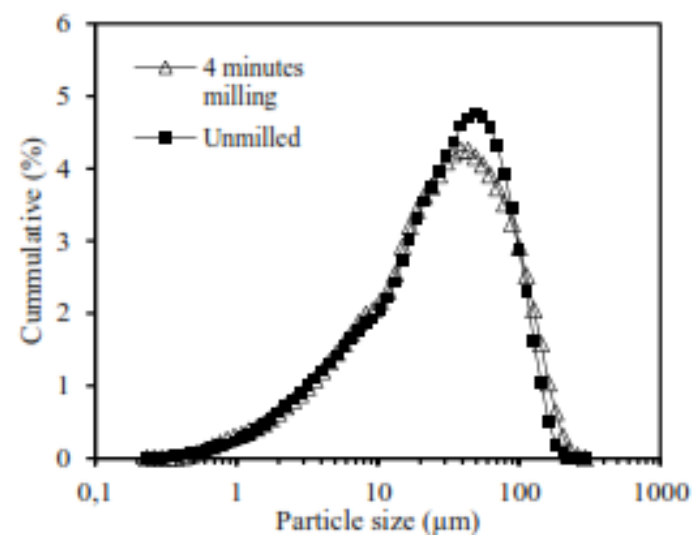

Fig. 5. Particle size distribution of unmilled and 4 minutes milling of INB

\subsection{Sorption study}

Effect of contact time can be seen in Fig. 6. Amount sorbed respect to time both unmilled and 4 minutes milling of INB. Sorption improvement of Mn shown after 4 minutes milling. Initially, adsorption rate increased rapidly, and the optimal sorption was reached around 24 hours. Further increase was not significant indicated reached equilibrium. The $\mathrm{pH}$ has risen became 7 in 30 minutes.

Table 2. Isotherm parameter

\begin{tabular}{|c|c|c|c|c|}
\hline \multirow[b]{2}{*}{$\begin{array}{l}\text { Isotherm } \\
\text { model }\end{array}$} & \multirow[b]{2}{*}{$\begin{array}{l}\text { Sample } \\
\text { condition }\end{array}$} & \multicolumn{3}{|c|}{ Isotherm parameters } \\
\hline & & $\begin{array}{c}q_{\max } \\
(\mathrm{mg} / \mathrm{g})\end{array}$ & $\begin{array}{c}K_{L} \\
(\mathrm{~L} / \mathrm{mg})\end{array}$ & 2 \\
\hline \multirow[b]{2}{*}{ Langmuir } & Unmilled & 0.570 & 0.029 & 0.605 \\
\hline & $\begin{array}{l}4 \text { minutes } \\
\text { milling }\end{array}$ & 4.219 & 0.457 & 0.962 \\
\hline
\end{tabular}

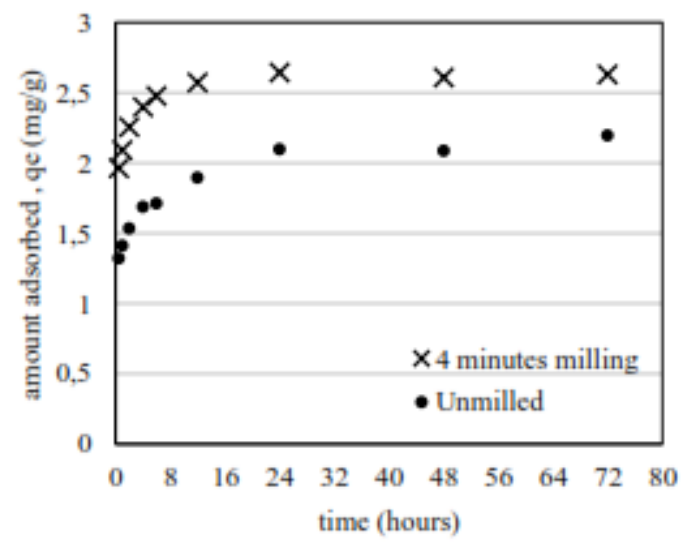

Fig. 6. Effect of contact time

Effect of adsorbent dosage can be seen in Fig. 7. Percentage removal was plot versus adsorbent dosage. Addition of adsorbent dosage slightly increased the percentage removal of $\mathrm{Mn}$. The percentage removal of 4 minutes milling of INB is improved and even almost reached $100 \%$ at $1.2 \mathrm{~g}$ dosage.

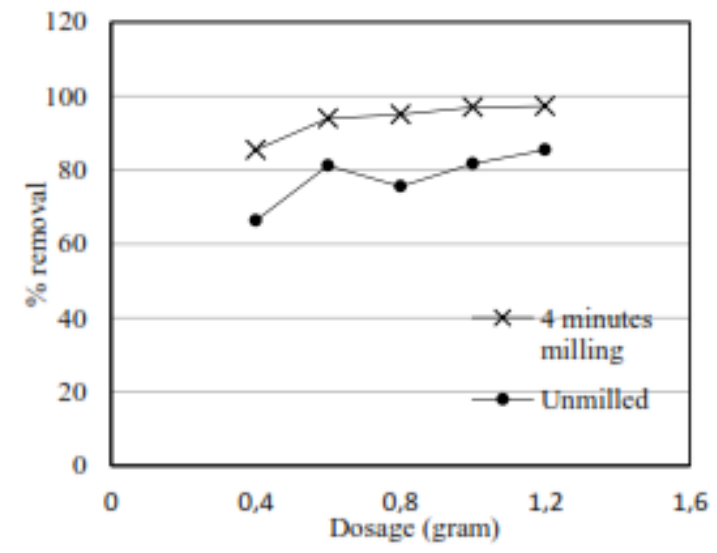

Fig. 7. Effect of adsorbent dosage

Isotherm is relationship between adsorbed amount and final concentration remains in solution. Langmuir isotherms was used to determine the type of sorption between adsorbate and sorbate. Langmuir isotherm is assumed the sorbate attached on surface of adsorbent as monolayer. Langmuir equation can be expressed as:

$$
q e=\frac{q_{\max } K_{L}}{1+K_{L} c_{e}}
$$

Where :

$q e=$ amount of solute sorbed per gram on sample (mg/gr)

$q_{\max }=$ amount of maximum solute sorbed per gram on sample (mg/gr)

$K_{L}=$ constant related energy of sorption $(\mathrm{L} / \mathrm{mg})$

$C_{e}=$ the equilibrium concentration of solute $(\mathrm{mg} / \mathrm{L})$

Langmuir isotherm plot is shown in Fig.8. The $\mathrm{q}_{\max }$ and $\mathrm{KL}$ can be calculated from slope $=1 / \mathrm{q}_{\max }$ value and intercept $=1 / \mathrm{KL} \cdot \mathrm{q}_{\max }$ value. The calculation result is shown in Table 2. The value of $\mathrm{q}_{\max }$ is increasing significantly, exhibits milling has brought on better sorption.

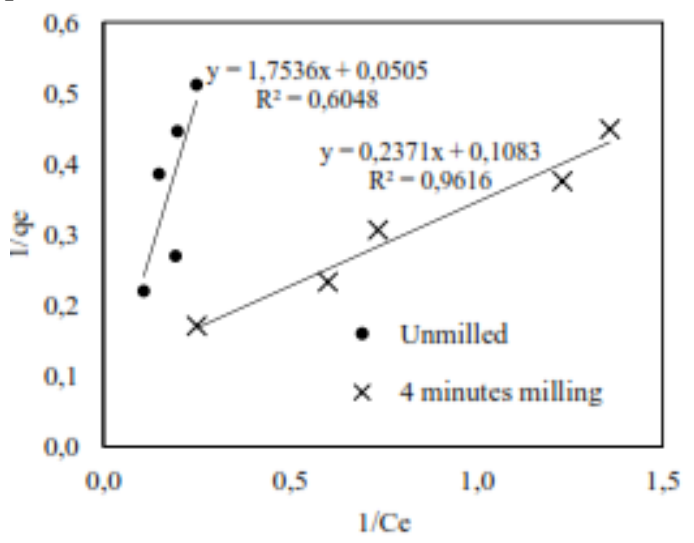

Fig. 8. Langmuir isotherm unmilled and 4 minutes milling of INB 


\section{Conclusion}

Left-right moving milling mechanism with $20 \mathrm{~Hz}$ in frequency during 4 minutes deformed the (001) montmorillonite but still remained the (100), indicated delamination without destruct the T-O-T structure. According to the significant increase in microporosity from the $t$ plot, but there was no significant change of $t$ plot, it is assumed the delamination did not fully separated between the T-O-T planes. Further study about equipment and energy effect, and mineral orientation after and before mechanical modification are needed.

The INB adsorption performance for Mn removal from AMD was improved by milling. The removal percentage, maximum adsorbed metal and the $\mathrm{pH}$ was successfully increased. However, milling optimization on INB need to be more investigated in order to get more maximum Mn removal and also for the other heavy metals. Milling and INB is promising as lowcost modification and low-cost material remediation.

\section{References}

1. R.E. Grim, Clay Mineralogy, McGraw-Hill Book Company (1968)

2. T. Al-Ani, O. Sarapää, Clay and Clay Mineralogy, Geological Survey of Finland (2008)

3. S. Budsaereechai, K. Kamwialisak, Y. Ngernyen, KKU Res. Jour. 17, 5, $800-810$ (2012)

4. M. El miz, S. Salhi, I. Chraibi, A. El Bachiri, M.L. Fauchonnier, A. Tahani, Open Jour. of Phys. Chem. 4, $98-116$ (2014)

5. V. Masindi, W. Gitari, Jour. of Env. Chem. Eng. 3, 2416-2425 (2015)

6. Djukic, U. Jovanovic, T. Tuvic, V. Andric, J.G. Novakovic, N. Ivanovic, L. Matovic, Ceramics Int., 39, 7173 - 7178 (2013)

7. A.R.Ramadan, A.M.K.Esawi, A.Abdel Gawad, App. Clay Sci. 47, 196-202 (2010)

8. N. Vdović, I. Jurina, S.D. Škapin, I. Sondi, App. Clay Sci. 48, $575-580$ (2010)

9. Indonesian Ministry of Energy and Mineral Resource, Indonesia Geological Resource: Book 3 : Java Island (2009)

10. Indonesian Government Regulation No. 82, Quality Management and Water Pollution Control (2001)

11. Regulation of Indonesian Ministry of Environment No. 113, Standard quality of waste water for industry and or coal mining activities (2003)

12. H.D. Chapman, Cation-Exchange Capacity, in: C.A.Black (Ed.), Method of Soil Analysis, Part 2: Chemical and Microbiological Properties, Am.Soc.Agron, Madison, Wisconsin, 891-900 (1965)

13. S. Kondo, T. Ishikawa, I. Abe, Science of adsorption (Kyuutyaku no kagaku), Maruzen Publisher (2001) (Japanese version only)
14. B. C. Lippens and J. H. de Boer, J. Catalysis 4, 319 (1965)

15. I. Sondi, M. Stubičar, V. Pravdić, Colloids and Surfaces A: Physicochemical and Eng. Aspects 127, 141-149 (1997) 